\title{
Examination of Surface Quality after Drilling of Wood Plastic Composite
}

\author{
Zuzana Mital’ová $^{1}$, František Botko ${ }^{1}$, Juliána Litecká ${ }^{2}$, Dušan Mital ${ }^{1}$ \\ ${ }^{1}$ Faculty of Manufacturing Technolgies of Technical University of Košice with seat in Prešov, \\ Bayerova 1, 08001 Prešov, Slovakia \\ ${ }^{2}$ Faculty of Humanities and Natural Sciences, University of Prešov, 17. November street - no. 1, \\ 08116 Prešov, Slovakia
}

\begin{abstract}
Presented article with machining (specifically drilling technology) of composite materials is based on Wood-Plastic Composite, in short WPC (as a minimum substitute for wood in interior / exterior applications). Experiment is focusing on selected technological parameters of machining (spindle speed and tool feed rate) on the characteristics of created surface. Surface cut zone quality - surface topography is examined by contact profilometry (as commonly available methods) and optical methods. The results of the experiments point to the disadvantages of these composite materials and the basic aspects influencing the quality of surfaces after machining is the inhomogeneity of the material.
\end{abstract}

Keywords - Wood Plastic Composite, drilling, machinability, mechanical properties.

\section{Introduction}

Drilling is one of the most important machining operations in the manufacturing process (any defect that leads to the rejection of the parts represents an expensive loss) [1].

DOI: $10.18421 /$ TEM111-40

https://doi.org/10.18421/TEM111-40

Corresponding author: Zuzana Mital'ová,

Faculty of Manufacturing Technologies of Technical University of Košice with seat in Prešov, 08001 Prešov, Slovakia

Email: zuzana.mitalova@tuke.sk

Received: 11 January 2022.

Revised: 09 February 2022.

Accepted: 14 February 2022.

Published: 28 February 2022.

(c) BY-Nc-ND (C) 2022 Zuzana Mital'ová et al; published by UIKTEN. This work is licensed under the Creative Commons Attribution-NonCommercial-NoDerivs 4.0 License.

The article is published with Open Access at https://www.temjournal.com/
In the connection to the examined problematics there is variety of scientific works: study of Polish authors compares drilling in dependence of changing thrust force [2]. They point out on better machinability of WPPC (matrix PE/PVC) in comparison to the wood specimens - specifically: alder / birch / beech. Next study compares machinability of three types of WPC - fibreboards, particle boards, and veneer boards. The experiment evaluates the quality of drilled holes and values of the cutting force and torque. Subsequently evaluates machinability indexes (in dependence on machined surface quality and cutting forces). The conclusion is clearly formulated: The quality index showed the influence of the internal structure and homogeneity of the different types of materials [3].

Papers of authors: Zuraik et al. from 2020 is focused on investigation of delamination factor for drilling of WPC (compares two methods of holes manufacturing - single step drill and 2-peck / 4-peck drills in dependence the entrance/exit drill from hole - delamination) [4]. Delamination and thrust force developed is reduced when small diameter drills are used in the drilling of wood composite panels [5], [6], [7]. Changing parameters of drilling process in dependence on resulting surface quality (of particle board composite panels) were studying [8]. Evaluated parameter $R a$ is for mentioned study in the range $6.03-28.32 \mu \mathrm{m}$, the minimum value of the mean arithmetic deviation of the profile was measured at the lowest value of the feed rate and smaller point angle combination. In the process of making holes, three types of drills were used - with apex angles: $100^{\circ}, 118^{\circ}, 135^{\circ}$ ). They applied analysis ANOVA and fuzzy inference system in the evaluation process. In addition to examining the changing parameters of the drilling process in relation to the quality of machined surfaces, the research is also focused on tool life / wear in machining composite materials with natural reinforcements (in general it can be stated that tool life in machining of these materials is relatively low) [9], [10], [11]. The problem with drilling also remains: the fibre pull-out, fibre debonding and the internal cracks, and the sticking of synthetic resins are the major issues in the machining of NFRCs [12] 
(the cited study provides an overview of the machining technologies of NFRCs, optimal process parameters and emerging problems in machining processes).

\section{Experimental Procedure}

Material: Experimental material was wood filled plastics (commercially manufactured sample) - with PE matrix and wood reinforcement (unspecified) in ratio: 30/70 \% (Figure 1). Experimental material exhibits: tensile strength $R m$ approximately $20 \mathrm{MPa}$ (experimentally found), elongation $A=3.05 \%$, contraction $Z=0.9 \%$ and deformation work is 17.6 $\mathrm{mJ}$ (experimentally obtained values are average values of set number of tested samples). Experimental material has relatively high life-time, ability to resist moisture /adverse weather/ pests and insects (when applied in extremely humid conditions, it is possible to apply resin from Guayele tree as a matrix, it is resistant to skidding (most of the characteristics are compared in relation to commonly available wood materials). Application: construction - building cladding, terraces / flooring - exterior flooring / furniture industry / automotive industry dashboards, luggage compartment bottoms (Volvo), door upholstery, ceilings, luggage compartment components (Mercedes), etc.

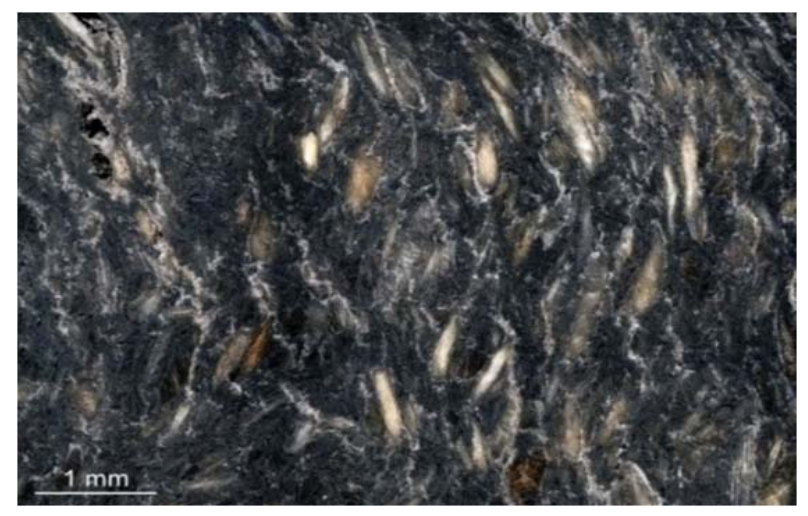

Figure 1. Examined material: Wood plastic Composite (Nikon Eclipse 80i) [13]

Experimental procedure: Prior to the drilling process, surface hardness values were measured (see description below). In relation to the fact that the measurement of the hardness of the wood-plastic material is not validated by the standardized methodology, the Leeb hardness assessment methodology (HLD, rebound method) was chosen as an alternative for comparative purposes. The evaluation was performed at 3 places in the volume of the extruded profile, and also on the surface of the extruded profile (Figure 2, Figure 3) on 5 samples with repeatability 11-times in each selected area. Portable hardness tester TH-1100 with integrated D-probe is applied. The measured values in each place were subjected to the Grubbs test (with a probability of $\quad p=95 \%$ ). Values subject to gross error were excluded from the set of values. The average values of the individual sites for the samples marked 1 to 5 are given in the Table 1 .

Table 1. Hardness values (arithmetic mean values) of samples marked from 1 to 5 in selected places of measurement (1-4)

\begin{tabular}{|c|c|c|c|c|}
\cline { 2 - 5 } \multicolumn{1}{c|}{} & \multicolumn{4}{c|}{$\begin{array}{c}\text { Measurement place (values of } \\
\text { arithmetic means-hardness) }\end{array}$} \\
\hline Sample no. & 1 & 2 & 3 & 4 \\
\hline Sample 1 & 358.9 & 285.7 & 299.7 & 501.9 \\
\hline Sample 2 & 323.4 & 232.7 & 235.6 & 524.6 \\
\hline Sample 3 & 347.1 & 247.7 & 240.5 & 520.5 \\
\hline Sample 4 & 353.8 & 224.6 & 259.5 & 517.5 \\
\hline Sample 5 & 368.4 & 235.1 & 195.2 & 511.4 \\
\hline
\end{tabular}

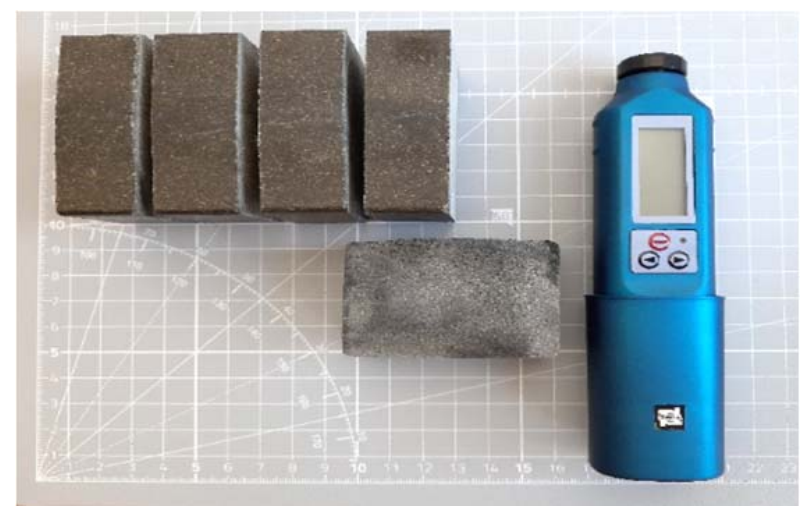

Figure 2. Evaluated samples (5 pieces, marked places of hardness measurement. In volume of extruded profile: 1middle, 2-left side, 3-right side / 4-surface of extruded profile)

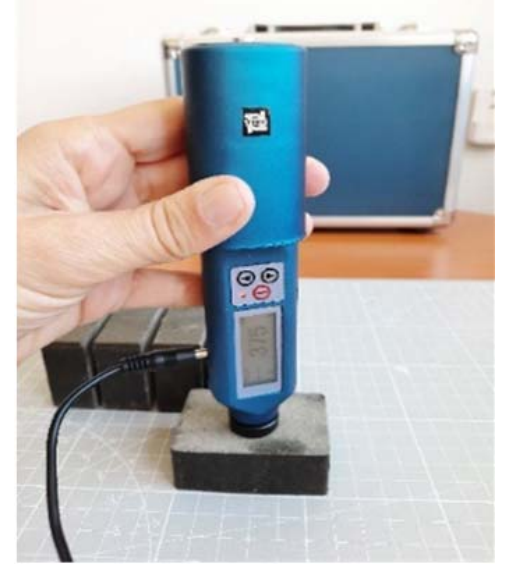

Figure 3. Principle of measurement in the middle of sample (in place 1)

There are obvious differences between the measured values in the individual areas. The hardness values at the edges of the examined profiles range from 195.2 to 299.7 HLD. In area 1 , in the volume of the examined profile they are of the order of magnitude higher (323.4-368.4 HLD). On the surface of the extruded profile, they reach approx. 500 HLD (values can be seen in Table 1). Figure 4 shows the dispersion of values (11 measurements) in individual areas of the profile volume (for area 1 to 3). 


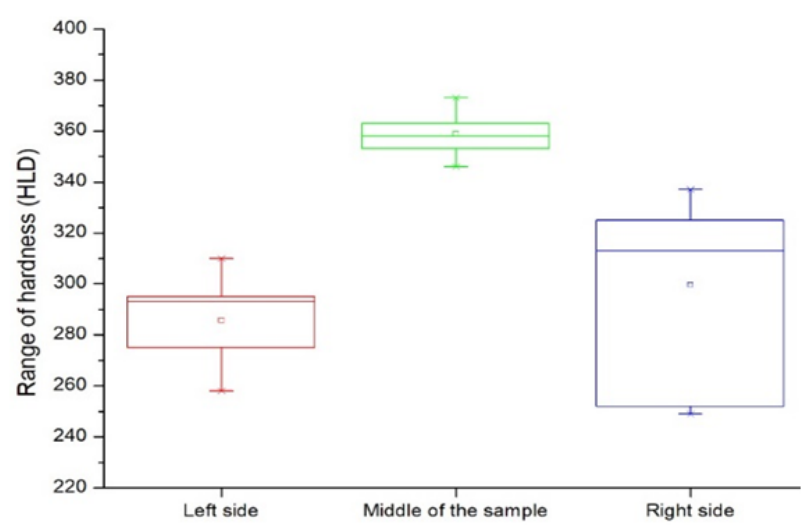

Figure 4. Principle of measurement in the middle of extruded profile (in place 1)

For experimental evaluation (drilling technology), a workpiece with the following dimensions was selected: $60 \times 40 \times 230 \mathrm{~mm}$ (width / height / length). A total of 9 through holes (a combination of varying speeds and feed rates) were then drilled into the workpiece. In all cases, the drilling process was carried out by means of a standard $\mathrm{CNC}$ machine tool (Pinnacle VMC650S) and the standard drills (with a diameter of 3-7 mm, with HSS + Ti coating). In the drilling process, a cycle was applied - flush drilling. The conditions of the cutting process were set as follows: spindle speed $n: 2000,4000,6000$ $\mathrm{rpm}$, feed rate $f_{n}: 100,200,300 \mathrm{~mm} \cdot \mathrm{min}^{-1}$. Before measuring the roughness parameters, it was necessary to cut the part along the holes (application of a band saw). Description of the experiment - see Table 2 and Figure 5.

Table 2. Description of experiment

\begin{tabular}{|c|}
\hline $\begin{array}{l}\text { Cutting process machine: drilling / cutting along } \\
\text { holes (before measuring surface roughness } \\
\text { parameters): Pinnacle VMC650S CNC vertical } \\
\text { machining center / BOMARERGONOMIC 275.230 DG } \\
\text { band saw. }\end{array}$ \\
\hline $\begin{array}{l}\text { Cutting tool and drilling cycle: Screw drill, high speed } \\
\text { steel with 5-8\% Co, titanium nitride (TiN) coating, } \\
\text { applied diameters: } 3 / 5 / 7 \mathrm{~mm} \text {. } \\
\text { With rinsing. After drilling the specified hole depth } 5 \\
\text { mm, the tool has returned to its initial position (due to } \\
\text { tool cooling / chip removal). He returned to the position } \\
\text { of the drilled depth at rapid traverse and continued } \\
\text { with the working traverse to the next section (by } 5 \mathrm{~mm} \text { ). } \\
\text { The cycle is repeated until the hole is completely } \\
\text { drilled. }\end{array}$ \\
\hline $\begin{array}{l}\text { Workpiece (drilled object): Prism measuring } 60 \times 40 \times \\
230 \mathrm{~mm} \text { (width / height / length). }\end{array}$ \\
\hline $\begin{array}{l}\text { Measuring instruments: Measurement of surface } \\
\text { roughness parameters: profilometer Mitutoyou SJ400. }\end{array}$ \\
\hline $\begin{array}{l}\text { Cooling emulsion: Not applied in relation to the nature } \\
\text { of the material, tool cooling provided by a specified } \\
\text { drilling cycle-with flushing. }\end{array}$ \\
\hline
\end{tabular}

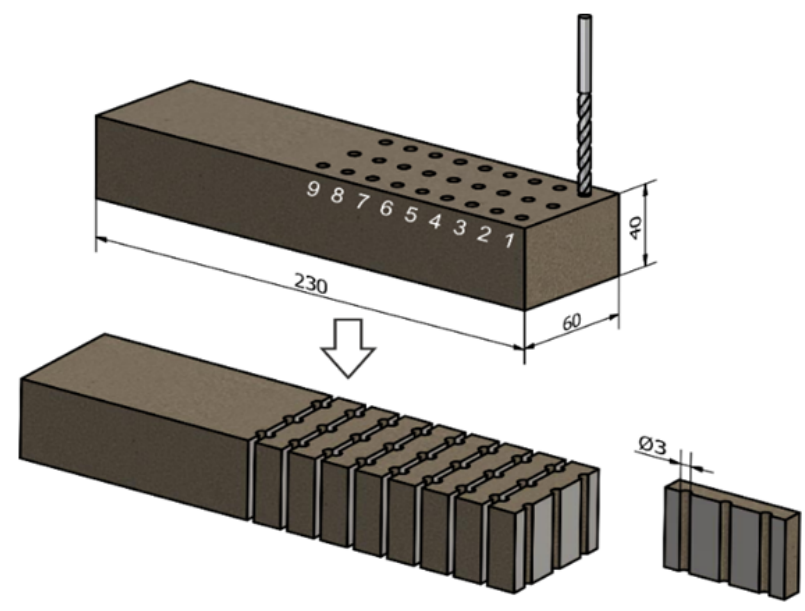

Figure 5. Methodology of sample preparation (before the measuring of surface roughness)

The surface roughness parameters were measured with a contact (contact) profile (length of the evaluated section $l_{r}=4 \mathrm{~mm}$, profile filter $\lambda_{c}=0.8 \mathrm{~m}$ ) in accordance with ISO 4287 [14]. The roughness parameters were measured in the core of the hole on the right / left with repetition (principle measurements - see Figure 6). Subsequently, a Grubbs test was performed to evaluate and work with the data, and an arithmetic mean of the 12 measurements performed was made. A digital microscope camera with a resolution of 2 MPix was applied for macroscopic evaluation of the surface.

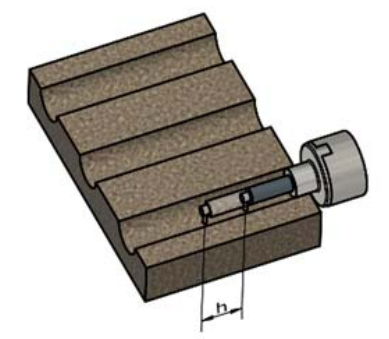

Figure 6. Principle of measurement by application of a touch profilometer (marking of holes)

From the measured values (in accordance with the mentioned standard) the parameters were subsequently assessed: $R z$ - the maximum height of profile average value / $R a$ (arithmetical mean deviation). The arithmetic means of the $\underline{R z} / R a$ parameter for individual applied tools are shown in the Table 3, Table 4, and Table 5.

Table 3. Ra parameter values for a diameter $3 \mathrm{~mm}$ tool (HSS + TiN coating)

\begin{tabular}{|c|c|c|c|}
\hline & \multicolumn{3}{|c|}{ Spindle speed $n$ [RPM] } \\
\hline $\begin{array}{l}\text { Feed rate } f_{n} \\
{\left[\mathrm{~mm}_{\mathrm{m}} \mathrm{min}^{-1}\right]}\end{array}$ & 2000 & 4000 & 6000 \\
\hline 100 & $1.45 \mu \mathrm{m}$ & $4.01 \mu \mathrm{m}$ & $2.52 \mu \mathrm{m}$ \\
\hline 200 & $2.03 \mu \mathrm{m}$ & $3.20 \mu \mathrm{m}$ & $2.65 \mu \mathrm{m}$ \\
\hline 300 & $2.86 \mu \mathrm{m}$ & $2.21 \mu \mathrm{m}$ & $3.91 \mu \mathrm{m}$ \\
\hline
\end{tabular}


Table 4. Ra parameter values for a diameter $5 \mathrm{~mm}$ tool (HSS + TiN coating)

\begin{tabular}{|c|c|c|c|}
\hline & \multicolumn{3}{|c|}{ Spindle speed $n$ [RPM] } \\
\hline $\begin{array}{l}\text { Feed rate } f_{n} \\
{\left[\mathrm{~mm}_{\mathrm{min}} \mathrm{min}^{-1}\right]}\end{array}$ & 2000 & 4000 & 6000 \\
\hline 100 & $1.89 \mu \mathrm{m}$ & $2.48 \mu \mathrm{m}$ & $2.90 \mu \mathrm{m}$ \\
\hline 200 & $2.65 \mu \mathrm{m}$ & $3.63 \mu \mathrm{m}$ & $3.60 \mu \mathrm{m}$ \\
\hline 300 & $2.79 \mu \mathrm{m}$ & $2.50 \mu \mathrm{m}$ & $3.46 \mu \mathrm{m}$ \\
\hline
\end{tabular}

Table 5. Ra parameter values for a diameter $7 \mathrm{~mm}$ tool (HSS + TiN coating)

\begin{tabular}{|c|c|c|c|}
\hline & \multicolumn{3}{|c|}{ Spindle speed $n$ [RPM] } \\
\hline $\begin{array}{l}\text { Feed rate } f_{n} \\
{\left[\mathrm{~mm}_{\mathrm{min}} \mathrm{min}^{-1}\right]}\end{array}$ & 2000 & 4000 & 6000 \\
\hline 100 & $2.37 \mu \mathrm{m}$ & $2.95 \mu \mathrm{m}$ & $4.77 \mu \mathrm{m}$ \\
\hline 200 & $2.85 \mu \mathrm{m}$ & $3.01 \mu \mathrm{m}$ & $3.75 \mu \mathrm{m}$ \\
\hline 300 & $3.08 \mu \mathrm{m}$ & $3.02 \mu \mathrm{m}$ & $3.90 \mu \mathrm{m}$ \\
\hline
\end{tabular}

Figure 7 shows the dependence of the mean arithmetic deviation of the unevenness profile $R a$ in relation to the changing spindle speed - for a $3 \mathrm{~mm}$ diameter drill. At feed rates of 100 and $200 \mathrm{~mm} . \mathrm{min}^{-}$ ${ }^{1}$, the dependences of the parameter $R a$ behave similarly - at a mean speed - $4000 \mathrm{rpm}$, the $R a$ values increase, and then decrease at maximum spindle speed. At a constant feed rate of 300 mm.min ${ }^{-1}$, the dependence tends to behave in opposite directions.

Figure 8 shows the dependence of the mean arithmetic deviation of the unevenness profile $R a$ in relation to the tool feed - for a $3 \mathrm{~mm}$ diameter drill. In the case of maximum and minimum speeds, the dependence of the parameter $R a$ in relation to the changing tool feed has an increasing tendency. The decreasing tendency is visible at medium spindle speed - $4000 \mathrm{rpm}$. The value of the surface roughness parameter decreases from $4.01 \mu \mathrm{m}$ (at a feed rate of $100 \mathrm{~mm} . \mathrm{min}^{-1}$ ) to $2.21 \mu \mathrm{m}$ (at a feed rate of $\left.\quad 300 \mathrm{~mm} \cdot \mathrm{min}^{-1}\right)$. This makes a difference of $1.8 \mu \mathrm{m}$.

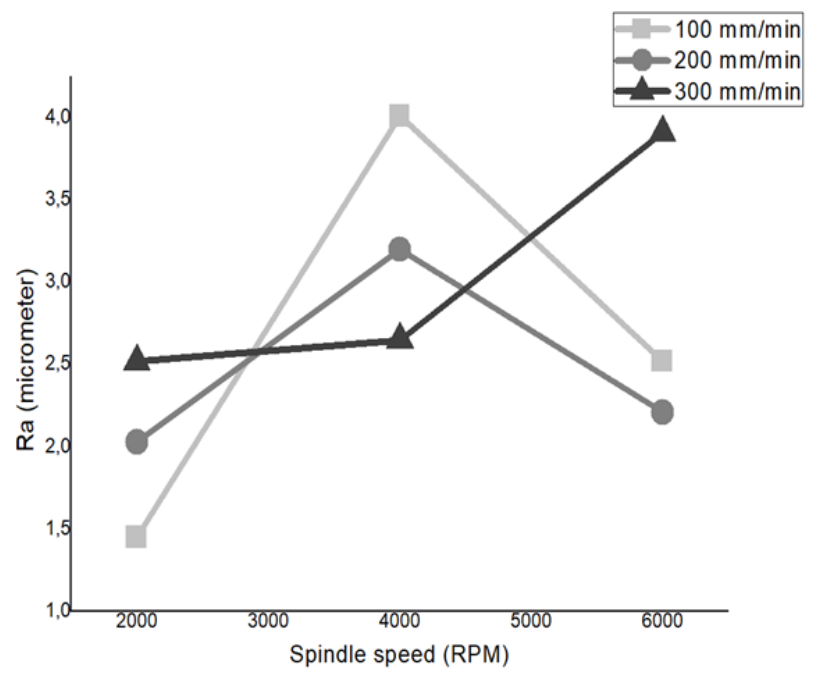

Figure 7. Representation of dependences of surface roughness parameter Ra in relation to changing: spindle speed

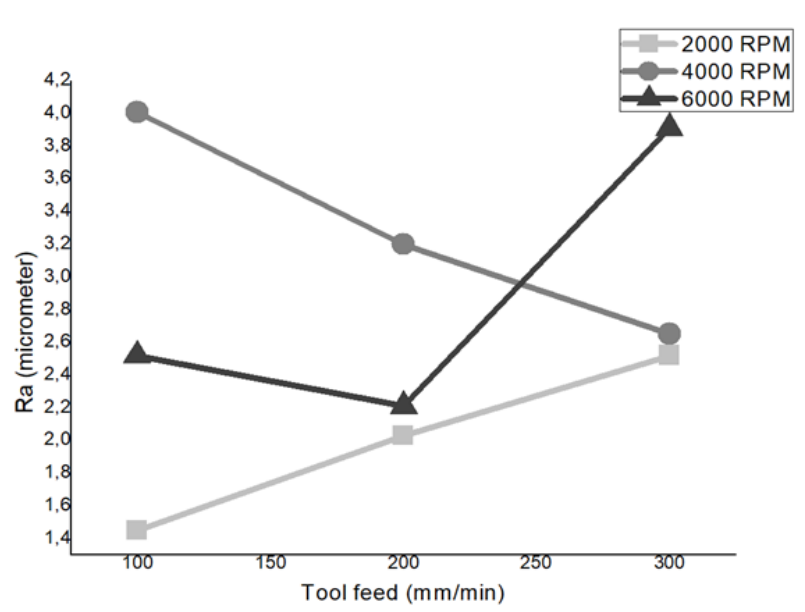

Figure 8. Representation of dependences of surface roughness parameter $R a$ in relation to changing: tool feed

Macroscopic evaluation of the created holes / tools: when drilling with TiN-coated HSS twist drills, the cross-sectional surface has the shape according to Figure 9. The surface of the hole has a "shiny" character (compared to the part of the material divided by a band saw). The shiny nature of the surface was caused by the melting of the plastic matrix of the material - during the passage of the tool. The surfaces after the cuts have regular shapes (there were no irregularities in the traces of the cutting part of the screw drill). Holes dark areas are visible on the surface of the holes. Dark areas were created as a result of the uneven structure of the composite material (the material has different character in different parts - it is inhomogeneous). In the process of drilling there was a so-called delamination - damage to the surface layer of material near the hole. When drilling with a tool with a small diameter $(3 \mathrm{~mm})$, the chip was not removed from the tool groove - which caused the material to melt and subsequently stick to the drill groove (Figure 9). This phenomenon did not occur with larger drill diameters. With a $7 \mathrm{~mm}$ diameter drill, the sticking of molten plastic on the secondary back surface of the drill is visible.

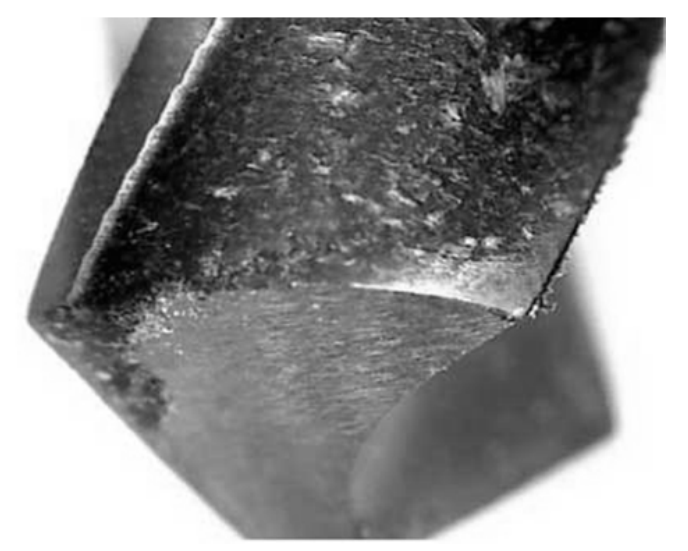

Figure 9. HSS twist drill - with coating (stick material to drill groove) [15] 


\section{Conclusion}

In the case of the investigated dependencies of the presented partial research, the theoretical statements were not fully confirmed: surface topography / cut quality significantly deteriorates with increasing feed rate, on the contrary it improves with increasing spindle speed: applied cutting speed. It is not possible to predict the behaviour of the parameters describing the quality of the resulting section in full (which is also confirmed by the literature in the introduction). The quality of the cut depends on the "material characteristics", which is also confirmed by the morphology images. The removal of the chip from the tool groove with smaller drill diameters is also problematic. In relation to the machined material - wood-filled plastic, its inhomogeneity and machinability index (in relation to the input components of the resulting composite material) play an important role.

\section{Acknowledgement}

This work was supported by the project VEGA 1/0080/20 (Research into the effect of high speed and high feed machining technologies on the surface integrity of hard-to-machine materials).

\section{References}

[1]. Naveen, P. N. E., Yasaswi, M., \& Prasad, R. V. (2012). Experimental investigation of drilling parameters on composite materials. J. Mech. Civ. Eng, 2, 30-37.

[2]. Pohl, P., Wolpiuk, M. (2010). Investigation on WoodPlastic Composite machinability during drilling. Woodworking Processes, 129-133.

[3]. Podziewski, P., Szymanowski, K., Górski, J., \& Czarniak, P. (2018). Relative machinability of woodbased boards in the case of drilling-Experimental study. BioResources, 13(1), 1761-1772.

[4]. Amirul Zuraik, M., Sobri, S. A., Asmawie Nik Abdullah, N., Hermawan, A., Mohamed, M., \& Afizi Shuaib, N. (2020, December). Preliminary Investigation of Delamination Factor for Drilling Wood Plastic Composites (WPC). In IOP Conference Series: Earth and Environmental Science (Vol. 596, No. 1, p. 012013).
[5]. Valarmathi, T. N., \& Palanikumar, K. (2013). Studies on delamination in drilling of particleboard (PB) wood composite panels. Proceedings of the Indian National Science Academy, 79(3), 339-345.

[6]. Davim, J. P., Clemente, V., \& Silva, S. (2007). Evaluation of delamination in drilling medium density fibreboard. Proceedings of the Institution of Mechanical Engineers, Part B: Journal of Engineering Manufacture, 221(4), 655-658.

[7]. Valarmathi, T. N., Palanikumar, K., Sekar, S. D. (2015). Review on modelling and optimalization of machining characteristics of composites. International Journal of Applied Engineering Research, 10(11), 10419-10424.

[8]. Valarmathi, T. N., Palanikumar, K., Sekar, S., \& Latha, B. (2020). Investigation of the effect of process parameters on surface roughness in drilling of particleboard composite panels using adaptive neuro fuzzy inference system. Materials and Manufacturing Processes, 35(4), 469-477.

[9]. Sheikh-Ahmad, J. Y., \& Bailey, J. A. (1999). Hightemperature wear of cemented tungsten carbide tools while machining particleboard and fiberboard. Journal of Wood Science, 45(6), 445-455.

[10]. Huang, S. T., Zhou, L., Chen, J., \& Xu, L. F. (2012). Drilling of $\mathrm{SiCp} / \mathrm{Al}$ metal matrix composites with polycrystalline diamond (PCD) tools. Materials and Manufacturing Processes, 27(10), 1090-1094.

[11]. Wang, X., Kwon, P. Y., Sturtevant, C., \& Lantrip, J. (2013). Tool wear of coated drills in drilling CFRP. Journal of Manufacturing Processes, 15(1), 127-135.

[12]. Rajmohan, T., Vinayagamoorthy, R., \& Mohan, K. (2019). Review on effect machining parameters on performance of natural fibre-reinforced composites (NFRCs). Journal of Thermoplastic Composite Materials, 32(9), 1282-1302.

[13]. Hutyrová, Z., Ščučka, J., Hloch, S., Hlaváček, P., \& Zeleňák, M. (2016). Turning of wood plastic composites by water jet and abrasive water jet. The International Journal of Advanced Manufacturing Technology, 84(5), 1615-1623.

[14]. ISO, E. (1997). 4287: 1997. Geometrical product specifications (GPS). Surface texture. Profile method. Terms, definitions and surface texture parameters. International Organization for Standardization, Geneva.

[15]. Hutyrová, Z., Zajac, J., Michalik, P., Mital, D., Duplák, J., \& Gajdos, S. (2015). Study of Surface Roughness of Machined Polymer Composite Material. International Journal of Polymer Science, 2015, 406-411. 